\title{
How do you tell them, "This will really work for you"?: DAM and how you can aid the creative process
}

\section{Russ Stanton}

Before moving into Information Technology (IT) in 1988, he developed a professional resume that encompassed television and radio production, producing/directing commercials and news magazine features for television. For his creative efforts, he was the recipient of 13 Addy Awards as Creative Director at WHNT-TV and a Gabriel Award at KYW-TV, Philadelphia as a producer for Evening Magazine. Most recently, he received a 2006 Aurora Gold Award and four 2007 Telly Awards, both for productions at BBDO. He is a regularly published writer and speaker at various video and DAMS conferences. For BBDO, he was one of the key architects in the creation of The Creative Library, a custom Digital Asset Management System that is considered "Best-of-Breed" in this space, and several articles have been published in periodicals such as Shoot, Millimeter, Videography, AdWeek andFilm \& Video. He recently transitioned from IT back to TV Production as Operations Director for The Kitchen, a postproduction studio and division of BBDO.

\section{Keywords: Creative, workflow, DAMS, production, challenges, culture}

Abstract For those of us in the Marketing and Advertising space, we have the distinct pleasure of working with a unique colleague known as the "Creative". BBDO is known as a creative agency and the creative group is responsible for the concepts and ideas that will make or break the company. The client has the ultimate say as to whether a concept will be used or not, but if an ad agency is worth its salt, it will make a strong case so that the client sees that these concepts will work to tell the message they want to get over to the customer. And, I have to say, not self-servingly, that we at BBDO do a remarkable job at that. Considering that influence, what kind of say do the Creatives really have in paving the way for adoption of digital asset management systems that will improve the way the work gets done, and can DAM truly benefit the Creative? Journal of Digital Asset Management (2007) 3, 177-180. doi:10.1057/palgrave.dam.3650084

Russ Stanton BBDO,

1285 Ave. of the America, New York, NY 10019. E-mail: Russ.Stanton@ bbdo.com

\section{WE'RE ALL IN THE SAME BOAT}

The basis for this article surfaced during the recent Henry Stewart Digital Asset Management Symposium in New York. I was privy to sit on a panel where the topic of how digital asset management can benefit the creative process was the focus. Enlightening to the panel and the audience was the fact that we had all experienced the exact same things in gaining adoption of workflow or DAM systems in the creative process. So, this article is something with which I think we all can identify.

For those of you in other types of industries such as manufacturing, shipping or others that on the surface do not seem to have that much to do with creativity, you may think that

"Creatives" do not have that much relevance for you. But, I will put this to you that even in the most technical or logistical of businesses, there is a creativeness that may escape the naked eye. But, it is there, regardless of that perception. So, I ask you to bear with me as it regards the typical creative process within the marketing and advertising space. I do believe you will see relevance no matter what type of business you are in.

One other point is that this is not truly a "how-to" paper where I am going to give you step-by-step instructions to use. This has more to do with the single biggest hurdle you will ever have to deal with in implementing DAMS in a creative environment. The Culture!!

If you can meet this challenge and win the adoption in the heart of the Creative Culture, the systems part of it will be a breeze and the rewards will be great. 


\section{THE CHALLENGE}

The Creative is the basis for all the concepts that are at the forefront of the advertising business and if your company is anything like the one I work for, the Creative carries a lot of weight in what goes and what does not. What kind of say do they have in adopting DAM. Well, they could have a lot of say, if it was a high priority to them. But, frankly, they have other things they would rather deal with and DAM is way down the list, if it is on the list at all.

Having been on both sides of the process, that is the creative and DAM systems (DAMS), I have been provided with a unique viewpoint when compared to most in our space. I know the frustration of having the creative community completely shun every effort to make their life easier when trying to implement meticulously thought-out workflows and systems. I have also been on the side of the creative thought where systems typically have no relevance to the concept being put forward.

That said, however, it sometimes still baffles me that the creative groups totally disregard how they could be working with what we call smarter applications, using tools that the IT groups or Operations might provide to them. But that's an emotional response and I should just listen to some of my own advice.

Also, and I believe most of my colleagues in the business will agree, the nature of advertising as an industry, in general, does not lead to rampant change such as utilizing DAM as a process improvement tool. The phrase "if it ain't broke don't fix it" runs prevalent in the advertising business as it pertains to the creative process because those ideas are typically fluidly created. That is, ideas come to the creative person at all hours and written on napkins at a bar, scribbled on anything handy on the train or plane and systems typically don't have a place in that kind of creation; nor should they, to be honest. After the initial stroke of brilliance, the creative person will typically get an art director involved and the process has begun, probably continuing with the napkin theme. To hell with the system, we're on a roll.

Now, there are segments of the creative business I have been involved with that do lend themselves to creation within a structure, such as news, talk shows or other types of production for television. I have seen television news workflows that hum along with incredible precision, and there are DAMS and procedures in place to help facilitate that. But if you think about it, they have to because the news happens all day and you're generating 5-6 hours of content everyday $24 \times 7 \times 365$. If you gave a second to ponder a concept outside of this structure, the Eyewitness news anchors would probably be silently staring at each other during most of the hour. In other words, the job just couldn't get done.

Advertising on the other hand is fluidly created and rehashed, over and over endlessly until, in the eye of the Creative Director, the right tone is reached and deadline rarely has a say in the matter, until you get to the production phase, but I digress. It is not out of the question to see 32 takes because of one word in the script. The phrase "Let's do one more" is probably the most common phrase heard on a commercial set. I guess what I'm trying to say is that the nature of advertising in general can be a hindrance to the adoption of a DAM-based workflow, mainly because of this fluidity.

This is reality and the sooner you realize that you have to live with this the faster you can move on to what really matters in getting DAMS implemented.

The mindset of a creative person is that of ideas, and it is our duty within this space not to interfere with whatever it takes to get those ideas flowing, whether it be doodling pads, flip charts, Bloody Marys or any other myriad of manual processes that send the typical systems person up a tree, wondering why these people can't put these ideas into some system to be tracked. It's simple, GET OVER IT!! No matter how impressive the system, the creative mind is what it is and to meddle with it can be a treacherous territory. By all means take the emotion out of the equation; mostly, for your own personal self-esteem. The creative process should not be tampered with no matter how frustrated you might get. It's not about you. It's about how the systems will still work to help make the creative process flow. And, therein lies the challenge. How do you still get that across?

At BBDO, we found out, after much hand wringing I must admit, that no matter how much you promote a system to the creative community, they really only want to concentrate 
on what they do best and quite honestly they should. The ideas and concepts they create are going to flow in whatever way they can, no matter what you do.

Business strategies in the advertising business obviously vary from agency to agency, but the bottom line is to get the message of the client across in as compelling a way as possible. These are typically generated by the account groups along with the client in what is known as the creative brief. This states in one page what the objective is, what audience you're trying to reach and how you're to go about it. The strategy in and of itself does lend itself to helping facilitate the adoption of some structure and thus a process, but it is just one small piece of the entire puzzle. The "brief" is referred to repeatedly to make sure things are on target, but usually by the account group and production. Creative groups can sometimes take off in another direction and achieve the goal, but not adhere to the "how-to" aspect of the brief, thus a departure from the process. If the concept is, however, compelling enough, this departure is signed off on and your structure is shot. Sometimes it's almost like shooting at a moving target.

So, I have always believed that if you believe in something, and you know that it works, then there are always alternatives that will make it work. And, patience is a virtue and can be a real benefit to what you're trying to achieve. In this case, take a lesson from the creative brief. Choose a different target audience to go after.

\section{ALTERNATIVES?}

In the advertising and marketing space, there are a variety of support people who take the concepts that those creative directors generate and they assemble the materials or assets through a sometimes-lengthy process. These could be anything from graphic artists, mechanical artists, video producers, copywriters, art directors and so on. These people are the ones in the trenches making it all happen. They are in production. These are the people to focus on, not the senior Creatives. So, you're probably thinking, "ahah, at last some structure to cling to and get the system adopted". Well, not so fast. It's not always quite that easy.

In the advertising business, there are certain workflows within these groups that you could possibly hang your structure on, but those can be hard to grasp in and of themselves. You see, a structure and workflow process in advertising is like getting a duck to wear shoes. It's just not natural. Even though the production people are more logistical than the creative group, they still see themselves as creative and thus repel any thoughts of structure. It is there, or else the spots or print ads just wouldn't get created. But to use the word process or workflow to them, you might as well tape the middle of your glasses together and proudly show off your new pocket protector. And that can certainly hinder any adoption of a DAMS-based workflow. I guess it comes down to something that advertisers had better know, or just turn off the lights. Know your audience and what will excite and engage them and what will turn them off in a heartbeat.

We all know that managing assets within a job can be a cumbersome process in any organization and structure within a production and creative group is a fleeting commodity. It can be done, however, given some of the things I'll talk about in the next section. The main objective is to remain objective and open to what they are trying to achieve and understand their goals as well as yours.

\section{WHO REALLY BENEFITS ANYWAY?}

This is a key question you have to ask yourself. In the creative process, are the systems really accessed and used by the creative people? If you answer honestly, it's probably no. So, you can save yourself a lot of time and frustration by finding out in the creative organization, or production for that matter, who actually manages how things get done and the creation of these assets. It may not be self-evident, but there are workflows in place, or as I said the work just wouldn't get done. Before you even think about a system to improve your workflow or the management of your assets, you really have to understand what the workflow is and who it is that makes it all happen. What kinds of personalities make up that culture?

In general, the culture of the advertising business, and especially the area of the culture you are targeting, can torpedo your effort before you get started. They are all creative to some 
aspect and therefore in love with their ideas and the way they do things. For those who have been doing it in the same space for a long time, the task of change is even more difficult, so time and patience had better be in your recipe. At $\mathrm{BBDO}$, this is especially the case since we have retained people here longer than most agencies. Unless you address this audience in a compelling way, this culture can certainly hinder adoption of any DAMS-based workflow. Oh, and please call it something else or you'll lose them right away. In a lot of ways, you have to create an advertising campaign yourself and use some smoke and mirrors, or computer-generated images to get your message across, just like they do for the clients.

But at the end of the day, these are the people who will gain the most benefit from what you're trying to do, and frankly they'll get it more, if you pitch it right and therein lies your success points.

Also, too often, those of us in this space try too hard to get sanction and promotion from the heavy-hitters in the organization. After all, the thinking goes, if the power brokers mandate it, then everyone else will have to adopt and use this system. There are failed implementations stacked high in the systems graveyard, given this thinking.

It's really a grassroots approach with the folks in the trenches that will get the work done. If you concentrate too heavily on top management, it will flounder. Those people performing their tasks to get the assets created can help you sell it to upper management if there is a necessity to do that for budgetary reasons. If you can sell what you're doing to them, you'll have an award-winning campaign.

Also a key to winning adoption of anything within the creative culture is to become one of the team. That means, don't mandate anything or set yourself up to seem superior to these people in any way, simply because you happen to know more about DAM than they do. Be humble and become one of them, take their advice when it comes to them doing their work and let their ideas flow. Use some of their creativity to help adopt your solution. In this culture, they need to feel like they contributed to everything they do. If it's dictated to them, you'll hear nothing but crickets.

Given this basic cultural methodology, DAMS can help facilitate the creative workflow but only if you have won over the culture. I don't care if you have a system that makes a latte at the same time; if you don't win the personalities, nothing will get adopted.

And, there are ancillary benefits as well. In the process, you may actually streamline workflows, making their job easier, product that is quicker to market and save the agency some money. Once you win them over to actually see what you're trying to do, you will have established a very positive audience for not only the DAMS, but you'll also have gained an ally who can help you in future implementations. Now that's a benefit for you, the agency, the creative group and something you all can take to the bank. 